\title{
0 ensino de metodologia de pesquisa na visão de alunos de Ciências Sociais e de Ciência Política
}

\author{
Bianca de Freitas Linhares*
}

\section{Resumo}

\begin{abstract}
Neste artigo, são apresentados dados resultantes da pesquisa Metodologia de Pesquisa: bases, técnicas e complementação dos protocolos quantitativo e qualitativo de conhecimento, desenvolvida no âmbito de bolsa de pós-doutorado Reuni, realizado entre 2011 e 2012 na Universidade Federal do Rio Grande do Sul. A pesquisa objetivou proceder a um diagnóstico sobre o ensino de metodologia de pesquisa entre alunos da pós-graduação em Ciência Política, bem como entre recém-egressos do curso de graduação em Ciências Sociais da instituição. Utilizando metodologia quantitativa, foi aplicado um survey junto aos discentes, entre os meses de janeiro e junho de 2012, buscando conhecer sua percepção sobre o tema analisado. A amostra foi selecionada em três estágios, tendo sido os dois primeiros por cotas e o terceiro por conveniência, totalizando cinquenta questionários. A pesquisa mostrou a necessidade de tratar de forma mais sistemática o ensino de metodologia, principalmente a metodologia quantitativa, junto ao corpo discente.
\end{abstract}

Palavras-chave: Ensino. Pesquisa. Metodologia. Corpo discente. UFRGS.

\section{Comentários iniciais}

O domínio da metodologia de pesquisa, sendo parte do fazer científico, é de fundamental importância para os acadêmicos. A relevância da metodologia recai em toda e qualquer pesquisa, na medida em que é por meio dela que se decidem os métodos e as técnicas que permitirão colocar a pesquisa em prática. Por sua vez, as técnicas empregadas devem estar de acordo tanto com a metodologia quanto com a teoria escolhida para tratar o objeto de pesquisa (LAKATOS; MARCONI, 1999). Todo pesquisador deve apresentar domínio dessa relação teoria - metodologia -

\footnotetext{
Recebido: 13/09/2013 - Aprovado: 20/12/2013

http://dx.doi.org/10.5335/rep.v21i1.3878
}

Doutora em Ciência Política pela Universidade Federal do Rio Grande do Sul (UFRGS), professora do Departamento de Sociologia e Política e do PPG em Ciência Política da Universidade Federal de Pelotas (UFPel). E-mail: bipolitica@ hotmail.com. 
técnicas de pesquisa. Tal domínio advém ao serem ultrapassadas certas barreiras e dificuldades encontradas durante a formação acadêmica, desde que o pesquisador seja despertado para a importância da temática.

É preocupação corrente entre professores universitários a formação acadêmica dos discentes com boa base em metodologia do trabalho científico, em metodologia e em técnicas de pesquisa. A mesma preocupação é verificada em relação aos alunos da área de Ciências Sociais e de Ciência Política da Universidade Federal do Rio Grande do Sul (UFRGS). Em especial, deve-se reter atenção à formação em metodologia de pesquisa e técnicas quantitativas (para além das técnicas qualitativas, para o que já é oferecido bom embasamento) com o intuito de proporcionar uma formação de excelência aos alunos. A importância de fortalecer essa parte da formação acadêmica dos alunos de Ciências Sociais e de Ciência Política está vinculada não só a uma formação mais completa e densa dos alunos de graduação visando à pós-graduação, mas também à sua preparação ao mercado de trabalho, cujas vagas, muitas vezes, são ocupadas por profissionais de outras áreas, como administração, economia, entre outras.

Pesquisa realizada por Barreto (2010) mostra que muitos dos egressos do curso de Ciências Sociais da UFRGS não conseguem inserir-se no mercado de trabalho para o qual foram formados. Esta conclusão corrobora a afirmação acima: a pesquisa, campo para o qual o cientista social deveria estar preparado, tem sido ocupada por profissionais formados em outras áreas. É possível que uma melhor qualificação do ensino de metodologia e de técnicas de pesquisa auxilie na inserção do corpo discente, ao final de sua formação de graduação, na atuação como pesquisadores em instituições que requeiram profissionais qualificados para essa área.

No âmbito da pós-graduação em Ciência Política, constata-se, em disciplinas do curso, que os alunos chegam a esse nível de ensino com lacunas na sua formação em metodologia do trabalho científico, metodologia de pesquisa e técnicas de pesquisa. Mesmo entre os que possuem graduação e/ou pós-graduação em Ciências Sociais - é importante lembrar que há alunos que advêm de outras áreas, que não oferecem formação em metodologia, pela qual as Ciências Sociais deve(ria)m passar -, verificam-se dificuldades, tanto em nível de mestrado quanto de doutorado, como a definição dos desenhos de pesquisa e das técnicas a serem utilizadas em seus trabalhos finais. Tal questão deve ser considerada com atenção, pois a dificuldade em definir o desenho de pesquisa mostra as limitações dos alunos quanto a tratar o seu objeto de pesquisa.

No desenho de pesquisa, definem-se estratégias metodológicas, técnicas de coleta e de análise de dados, bem como a população e unidades de análise a serem alcançadas (ROTMAN, 2006). Para tomar essas decisões, é importante sopesar 
vários pontos: a base teórica que servirá de esteio para a pesquisa, os objetivos da pesquisa, o tempo disponibilizado para todo o processo (desde a elaboração da proposta de trabalho até a redação final), o acesso ou o levantamento dos dados (considerando tempo, disponibilidade orçamentária e, dependendo do caso, acesso às unidades de análise), a necessidade e a obtenção de financiamento. Várias são as possibilidades de explicar essa lacuna dos alunos: falta de interesse por parte dos discentes em obter ou aprofundar seu conhecimento em metodologia, falta de acesso a essa formação, fragmentação do ensino de metodologia ao longo da vida acadêmica, problemas do modelo de ensino de metodologia e de técnicas de pesquisa verificados ainda na graduação.

Muitas vezes, os alunos, ao pensarem em metodologia científica, limitam-na à aplicação de normas de apresentação de trabalhos, a exemplo das normas da Associação Brasileira de Normas Técnicas (ABNT). Em outras situações, a veem como desnecessária e imposta por disciplinas obrigatórias, sem considerar, portanto, que, se são obrigatórias, tais disciplinas possuem algo de relevante para a sua formação. É papel dos docentes transmitir o que uma base acurada de metodologia científica possibilitará aos alunos, ou seja, as ferramentas para a construção do conhecimento. Nesse sentido, é relevante ter clareza sobre o que é o conhecimento científico, caracterizado por Lakatos e Marconi (1991) como: real (se dá com base em fatos); contingente (suas hipóteses são testadas por experimentação); sistemático (segue uma ordem lógica que se fundamenta em uma teoria); verificável (suas hipóteses passam pelo processo de verificabilidade); falível (não é conhecimento que se pretenda correto eternamente); aproximadamente exato (um novo arcabouço de proposições e técnicas pode mudar o que entendemos como correto ou verdadeiro).

Essas características trazem consigo a importância da formação metodológica para qualquer cientista. É a partir do conhecimento metodológico que se traça o "como" de uma pesquisa científica, e essa decisão implica diferentes âmbitos. Dependem da metodologia questões como a montagem da equipe de trabalho, o tempo de execução, o cronograma de atividades e o orçamento (a ser buscado, via de regra, em financiamentos por meio de editais de agências de fomento). Essas questões são definitivas para o sucesso de uma pesquisa científica. Da mesma forma, uma decisão metodológica insensata e/ou incorreta, seja no desenho de pesquisa, na sua aplicação ou na seleção dos dados para um relatório, pode colocar sua credibilidade em risco.

Entretanto, como é possível cobrar um posicionamento científico discente se, muitas vezes, não há um comprometimento docente com esse tema? A própria prática de pesquisa no país é algo que, de acordo com Severino, ainda precisa ser mais aplicada: 
Tenho por hipótese, no entanto, que a principal causa intramuros do fraco desempenho do processo de ensino/aprendizagem do ensino superior brasileiro parece ser mesmo uma enviesada concepção teórica e uma equivocada postura prática, em decorrência das quais pretende-se [sic] lidar com o conhecimento sem construí-lo efetivamente mediante uma atitude sistemática de pesquisa, a ser traduzida e realizada mediante procedimentos apoiados na competência técnico-científica. Muitos teóricos, especialistas em educação, assim como muitas autoridades da área, não conseguem entender a necessidade da postura investigativa como inerente ao processo do ensino. Daí inclusive defenderem a existência de dois tipos de universidades: as universidades de ensino e as universidades de pesquisa (2009, p. 10).

Embora haja alguma predisposição em separar ensino e pesquisa nas universidades, trabalhos recentes sobre os currículos de cursos da área de ciências sociais no Brasil mostram que as faculdades e pós-graduações apresentam aos alunos disciplinas sobre metodologia ${ }^{1}$. No entanto, a prática de pesquisa, seja em estágios (remunerados ou não), seja em bolsas de iniciação científica ou como aluno voluntário, não é obrigatória. Sendo assim, para a maior parte dos discentes, a prática de pesquisa fica limitada às disciplinas que realmente a oferecem. $\mathrm{E} o$ acesso às diversas técnicas de pesquisa, tanto qualitativas quanto quantitativas, são, muitas vezes, cingidas pela prática pessoal do docente responsável pela disciplina. $\mathrm{O}$ Relatório Wahlke ${ }^{2}$, mesmo tendo sido escrito para a realidade norte-americana, faz sentido no que se refere ao caso brasileiro, ao apontar que

[...] os estudantes devem ser expostos às diferentes abordagens e aos diferentes métodos e enfoques analíticos existentes na Ciência Política; os departamentos devem expor seus estudantes aos diversos subcampos existentes na disciplina, bem como às disciplinas próximas, como História, Economia, Geografia, entre outras, todas de elevada importância para o entendimento dos fenômenos do mundo político; os cursos de Ciência Política deveriam fornecer aos seus estudantes o conhecimento e as habilidades necessárias para compreender as análises políticas e desenvolver sua capacidade analítica, através do ensino de filosofia da ciência, de métodos de pesquisa, de estatística básica, de habilidades de escrita, uso de programas de computador para análise de dados e de experiência em pesquisa (Wahlke, 1991) (OLIVEIRA; NICOLAU, 2012, p. 2).

A pesquisa aqui apresentada teve como objetivo primordial diagnosticar a opinião e a percepção dos alunos de graduação em Ciências Sociais e de pós-graduação em Ciência Política da UFRGS sobre o ensino de metodologia e de métodos quantitativos. A importância de verificar a percepção dos alunos reside na concepção de que, em última instância, são eles, enquanto receptores de informação do corpo docente, que melhor podem indicar de que maneira o ensino de metodologia e de métodos quantitativos está sendo conduzido. Ademais, esse diagnóstico é importante porque permite que se saia do campo das "impressões" tidas em relação ao ensino de metodologia junto aos alunos, para se começar a compreender as reais limitações que o corpo discente enfrenta. Isso é relevante, pois, como afirma Monika Zulauf,

Alguns autores têm abordado a falta de atenção à visão dos estudantes. Bennett et al. (2000), por exemplo, apontam para a ausência de pesquisa empírica sobre: a opinião do estudante quanto à provisão de habilidades genéricas; as experiências dos estudantes; os 
resultados observados de diferentes formas de provisão de habilidades e a transferência do lugar para a aquisição da habilidade para os locais de trabalho. Muitos anos se passaram, e as opiniões e experiências dos estudantes continuam, em grande parte, ausentes da pesquisa e do debate (Shah et al., 2004; Burke et al., 2005) (2006, p. 126-127).

Assim, este artigo apresenta o diagnóstico do estado do ensino de metodologia de pesquisa entre recém-egressos ${ }^{3}$ da graduação em Ciências Sociais e de alunos de pós-graduação em Ciência Política da UFRGS. Os dados provêm da pesquisa Metodologia de Pesquisa: bases, técnicas e complementação dos protocolos quantitativo e qualitativo de conhecimento. A investigação fez parte das atividades desenvolvidas no âmbito da bolsa de pós-doutorado Reuni-UFRGS ${ }^{4}$, vinculada ao PPG em Ciência Política da UFRGS. Os dados mostram que o estudo da metodologia precisa ser reforçado nos dois níveis de ensino, além de deixar de ser objeto pontual de determinadas disciplinas, nas quais muitas vezes é entendida isolada da teoria.

Este texto está estruturado em três seções, além desta introdução e da conclusão. Na primeira parte, descreve-se os objetivos (geral e específicos) da pesquisa. $\mathrm{Na}$ segunda, são abordados os principais aspectos da metodologia e técnicas empregadas para a análise dos dados. Os dados são apresentados e analisados na terceira seção.

\section{Objetivos}

O objetivo norteador da pesquisa foi realizar um diagnóstico sobre o ensino de metodologia, com foco no ensino de metodologia e de técnicas de pesquisa quantitativa, junto aos alunos de graduação em Ciências Sociais e de pós-graduação em Ciência Política da UFRGS.

A partir desse objetivo central, foram desenvolvidos alguns objetivos específicos, quais sejam:

1) verificar o nível de aprendizagem sobre metodologia de pesquisa e de técnicas de pesquisa quantitativa junto aos alunos;

2) compreender as principais diferenças quanto ao ensino de metodologia de pesquisa e de técnicas de pesquisa quantitativa entre alunos de graduação e de pós-graduação;

3) averiguar o interesse dos alunos no aprendizado de métodos de pesquisa quantitativa;

4) classificar o ensino de metodologia segundo a visão dos alunos.

Com base nesses objetivos (e nas demais questões abordadas na parte inicial deste texto), são apresentadas, a seguir, as técnicas empregadas para alcançá-las, bem como a metodologia empregada na pesquisa. 


\section{Metodologia}

A pesquisa foi realizada utilizando metodologia quantitativa. Para tanto, a coleta de dados foi efetuada por meio de questionário ${ }^{5}$, composto em sua maior parte de perguntas fechadas (ver Apêndice). O universo de pesquisa são os alunos de Ciências Sociais e de Ciência Política da UFRGS. A população na qual foi aplicado o survey ${ }^{6}$ é formada por alunos divididos em três grupos. O primeiro grupo é o de alunos que estavam em condição de "formandos" no curso de Ciências Sociais no período 2011/2; o segundo, de alunos que estavam concluindo o mestrado em Ciência Política nesse mesmo período (alunos com entrada no curso de mestrado em 2010); o terceiro, de alunos que compuseram a turma de mestrado em Ciência Política com entrada na pós-graduação no ano de 2012.

O objetivo principal de compor a população dessa forma foi fazer uma comparação entre a formação dos alunos que estavam concluindo a graduação, a formação daqueles que já haviam obtido formação de pós-graduação (ou que estavam concluindo seus estudos nesse período) e a formação dos que estavam ingressando no mestrado (turma de 2012) - reunindo esses dois últimos grupos alunos provenientes de distintos cursos de graduação e de instituições diversas. Dessa forma, é possível verificar três etapas de formação: aqueles que, recém-formados, estavam se dirigindo ao mercado de trabalho (formandos 2011/2), os que estavam entrando para a formação acadêmica complementar (nova turma de mestrado de 2012) e os que estavam saindo dessa etapa.

Inicialmente, objetivava-se realizar um censo com a população. Nesse sentido, a partir de listagem com algumas informações dos alunos de graduação (fornecido pela comissão organizadora de formatura e Comissão de Graduação de Licenciatura e Bacharelado em Ciências Sociais - Comgrad/UFRGS) e de pós-graduação (fornecido pela secretaria do PPG em Ciência Política), os alunos foram contatados, buscando o agendamento das entrevistas. Esse primeiro contato foi realizado via e-mail e telefone.

Percebeu-se certa resistência dos alunos em participar da pesquisa, o que pode estar ligado a várias questões, como o fato de alguns estarem com suas defesas de dissertação "atrasadas" (caso da turma de mestrado com entrada em 2010); temor de represálias pela instituição em caso de se conseguir identificar os questionários com os nomes dos alunos; mal-estar em se falar sobre metodologia, talvez pela sensação de falta de domínio na área; não concordância com a importância da pesquisa.

Essa dificuldade de convencer os alunos a participarem da pesquisa revela, de antemão, um fato interessante para profissionais da área de Ciências Sociais: trata-se de um grupo que deve ou deveria saber a importância da participação da população em levantamentos de dados empíricos. No entanto, pelos motivos apontados, a rejeição em responder o questionário foi grande. 
Portanto, mesmo ressaltando-se o objetivo da pesquisa e a sua importância, foram impostas limitações à coleta de dados, como a indisponibilidade de um amplo número de alunos para responderem ao questionário. Então, considerou-se a proposta de um desenho amostral.

Os dados levantados resultaram de uma amostra em três estágios, sendo os dois primeiros por cotas e o terceiro por conveniência. Na amostragem por cotas, divide-se a população em subgrupos que convirjam em algum parâmetro. No caso, o parâmetro utilizado foi o nível de ensino. Considerando que as cotas são contabilizadas de acordo com a proporção de cada subgrupo na população, no primeiro estágio por cotas obteve-se dois grandes subgrupos: os respondentes de nível de graduação e os de nível de pós-graduação. Em seguida, no segundo estágio por cotas, o subgrupo de pós-graduação foi analisado de forma a indicar a proporção de respondentes que deveriam ser ingressantes no mestrado (2012) e a quantidade de entrevistados que deveriam ter entrado no mestrado em 2010. O terceiro estágio da amostra deu-se de forma aleatória, mas de acordo com a acessibilidade dos respondentes.

Dessa forma, do total de 58 alunos que estavam se formando em 2011/2, obteve-se 30 questionários, que foram aplicados em janeiro de 2012 face a face ou por telefone. Na turma do mestrado em Ciência Política que teve seu ingresso em 2010, foram aplicados 8 questionários (de um total de 14 alunos). Da turma com ingresso em 2012, dos 24 alunos admitidos, 12 responderam à pesquisa. Para ambas as turmas de mestrado, os questionários foram aplicados em maio e junho de 2012, também face a face ou por telefone. A amostra totalizou 50 respondentes.

Para o tratamento dos dados, foi construído um banco de dados no software SPSS $^{\circledR}$. Assim, foram geradas tabelas com dados descritivos e inferenciais, as quais são apresentadas a seguir.

\section{A metodologia de pesquisa junto aos discentes}

As principais informações sobre a percepção da população estudada acerca do ensino de metodologia passam a ser apresentadas nesta seção. Primeiramente, são descritos dados gerais, como gênero, idade, curso e ênfase (no caso da graduação, os formandos em Ciências Sociais estavam cursando a faculdade com ênfase na licenciatura e/ou no bacharelado). A seguir, busca-se atingir os objetivos elencados anteriormente.

A amostra foi composta por $56 \%$ de homens e $44 \%$ de mulheres. A média de idade atingiu 27 anos, tendo os mais jovens da amostra 21 anos e o mais velho, 52 . Quando observados a partir dos grupos aos quais se vinculam, a média de idade sobe para a graduação (média de 29 anos) e cai na pós-graduação (média de 26 anos). 
Sobre o curso ao qual estava vinculado quando da aplicação da pesquisa, $60 \%$ estava na graduação em Ciências Sociais e $40 \%$ no curso de mestrado em Ciência Política, conforme definido pelas cotas. Dentre os então alunos de graduação, $45 \%$ estavam habilitando-se na licenciatura e $55 \%$ no bacharelado. Como os dados foram levantados em 2012, o grupo de alunos com entrada na pós-graduação em 2012 encontrava-se no mestrado. Já dentre os alunos de mestrado com entrada em 2010, 5 declararam estar cursando o doutorado (todos em Ciência Política).

Para atingir o primeiro objetivo, qual seja, verificar o nível de aprendizagem sobre metodologia de pesquisa e de técnicas de pesquisa quantitativa junto aos alunos, foram realizadas algumas frequências. A primeira delas versa sobre o conhecimento de métodos quantitativos, e a segunda, sobre técnicas de pesquisa. A seguir, são apresentadas frequências sobre conhecimento de softwares de pesquisa e, especificamente, sobre o SPSS, que é um software de análise quantitativa, especificamente desenvolvido para a área de Ciências Sociais e bastante utilizado na UFRGS.

Tabela 1 - Possui conhecimento sobre métodos quantitativos (\%)?

\begin{tabular}{l|c}
\hline Opinião & $\%$ \\
\hline Sim & 84 \\
Não & 16 \\
Total & 100 \\
\hline
\end{tabular}

Fonte: Pesquisa Metodologia de Pesquisa: bases, técnicas e complementação dos protocolos quantitativo e qualitativo de conhecimento (2012).

Tabela 2 - Conhece algumas técnicas de pesquisa (\%)?

\begin{tabular}{l|c}
\multicolumn{1}{c|}{ Opinião } & $\%$ \\
\hline Sim & 86 \\
Não conhece & 6 \\
Não sabe & 8 \\
Total & 100 \\
\hline \multicolumn{2}{c}{$n=50$}
\end{tabular}

Fonte: Pesquisa Metodologia de Pesquisa: bases, técnicas e complementação dos protocolos quantitativo e qualitativo de conhecimento (2012). 
Os dados da Tabela 1 indicam que a maior parte dos alunos pesquisados possui algum tipo de conhecimento sobre métodos quantitativos. No entanto, $16 \%$ dos entrevistados vão para o mercado de trabalho sem noção alguma desse protocolo de conhecimento. Esse fato revela uma questão bastante preocupante: todo cientista social ou cientista político deve (ou, ao menos, deveria) deter conhecimento acerca dos protocolos de conhecimento quantitativo e qualitativo; assim, no momento em que uma parcela desses recursos humanos se gradua sem conhecimento de um desses protocolos, resta evidenciada a fragilidade da sua formação educacional. Essa questão será retomada mais adiante, ao ser tratada segundo o nível de formação da população.

Nesse mesmo sentido, a Tabela 2 indica que $86 \%$ dos alunos conhecem algum tipo de técnica de pesquisa. Contudo, $14 \%$ dos entrevistados não conhecem qualquer técnica de pesquisa ou não sabem responder a esse questionamento. Essa declaração dos discentes levanta séria preocupação sobre a formação de profissionais oriundos das Ciências Sociais e da Ciência Política, pois é imprescindível a um cientista social ou político deter esse conhecimento, mesmo que, a princípio, pense não ser necessário para sua vida profissional. Aos estudantes que responderam conhecer técnicas de pesquisa (86\%), solicitou-se que nomeassem algumas. Do total de respostas obtidas, consideraram-se apenas as que realmente são técnicas de pesquisa. Assim, do total de respostas, cerca de $72 \%$ são relacionadas à metodologia qualitativa. Tal dado mostra que a metodologia quantitativa, apesar de ser tratada em algum momento da vida acadêmica, é insuficientemente trabalhada e resulta pouco fixada na memória desses estudantes.

Os dados das Tabelas 3 e 4 mostram o conhecimento da população estudada sobre softwares de pesquisa.

Tabela 3 - Conhece o software SPSS (\%)?

\begin{tabular}{l|c}
\hline \multicolumn{1}{c|}{ Opinião } & $\%$ \\
\hline Sim & 86 \\
Não & 14 \\
Total & 100 \\
\hline \multicolumn{2}{c}{$n=50$}
\end{tabular}

Fonte: Pesquisa Metodologia de Pesquisa: bases, técnicas e complementação dos protocolos quantitativo e qualitativo de conhecimento (2012). 
Tabela 4 - Já ouviu falar sobre outros softwares (qualitativos ou quantitativos) de pesquisa (\%)?

\begin{tabular}{l|c}
\multicolumn{1}{c|}{ Opinião } & $\%$ \\
\hline Sim & 64 \\
Não & 30 \\
Não sabe & 6 \\
Total & 100 \\
\hline \multicolumn{2}{c}{$n=50$}
\end{tabular}

Fonte: Pesquisa Metodologia de Pesquisa: bases, técnicas e complementação dos protocolos quantitativo e qualitativo de conhecimento (2012).

Os dados das tabelas acima indicam que $86 \%$ dos entrevistados conhecem o software SPSS ${ }^{\circledR}$, um dos mais utilizados para pesquisa quantitativa em Ciências Sociais. Ao mesmo tempo, 64\% deles têm conhecimento de outros softwares de pesquisa, sejam qualitativos ou quantitativos. Àqueles que se posicionaram no sentido de saberem de outros softwares de pesquisa (64\% da população), foi solicitado que os listassem. Das respostas obtidas, foram excluídas as que não se enquadravam como softwares de pesquisa, e das respostas válidas, $51 \%$ referem-se a softwares qualitativos. O software quantitativo mais citado foi o Excel $^{\circledR}$, e o qualitativo, o Nvivo ${ }^{\circledR}$.

Os dados das tabelas apresentadas até aqui mostram certo domínio da metodologia qualitativa de pesquisa pelos alunos de Ciências Sociais e de Ciência Política. As perguntas abertas que elucidam essa questão evidenciam, também, certa prevalência de técnicas e de softwares de pesquisa qualitativos por parte dos pesquisados.

Os próximos dados buscam a compreensão das principais diferenças quanto ao ensino de metodologia de pesquisa e de técnicas de pesquisa quantitativa entre alunos de graduação e de pós-graduação. Apresenta-se a diferença dos níveis de ensino em relação ao conhecimento de métodos quantitativos e um mapeamento da origem de tal conhecimento.

Tabela 5 - Nível de formação X Possui conhecimento sobre métodos quantitativos (\%)?

\begin{tabular}{l|c|c}
$\begin{array}{c}\text { Possui } \\
\text { conhecimento }\end{array}$ & $\begin{array}{c}\text { Graduação em } \\
\text { Ciências Sociais }\end{array}$ & $\begin{array}{c}\text { Pós- graduação em } \\
\text { Ciência Política ** }\end{array}$ \\
\hline Sim & 87 & 80 \\
Não & 13 & 20 \\
Total & 100 & 100 \\
\hline \multicolumn{2}{c}{}
\end{tabular}

Fonte: Pesquisa Metodologia de Pesquisa: bases, técnicas e complementação dos protocolos quantitativo e qualitativo de conhecimento (2012). 
Tabela 6 - Nível de formação X Esse conhecimento advém de (\%)

\begin{tabular}{l|c|c}
\hline \multicolumn{1}{c|}{ Conhecimento prévio } & $\begin{array}{c}\text { Graduação em } \\
\text { Ciências Sociais * }\end{array}$ & $\begin{array}{c}\text { Pós- graduação em } \\
\text { Ciência Política ** }\end{array}$ \\
\hline Disciplinas cursadas & 96 & 69 \\
Cursos extracurriculares & 23 & 19 \\
Autodidata & 19 & 44 \\
Participação em pesquisas & $40^{\star \star \star}$ & 31 \\
\hline
\end{tabular}

$$
{ }^{*} n=26{ }^{* *} n=16{ }^{* * *} n=25
$$

${ }^{1}$ Os dados da tabela não somam 100\%, por se tratar de questão de múltipla escolha.

Fonte: Pesquisa Metodologia de Pesquisa: bases, técnicas e complementação dos protocolos quantitativo e qualitativo de conhecimento (2012).

Os dados acima indicam que mais alunos de graduação (87\%) do que de pós-graduação (80\%) afirmam ter conhecimento sobre metodologia quantitativa. Para os alunos de graduação, esse conhecimento é fruto, principalmente, de disciplinas cursadas e de participação em pesquisas (como bolsista de iniciação científica, ou outras formas de atuação em grupos/empresas de pesquisa). Também com os alunos de pós-graduação o contato foi realizado, principalmente, em disciplinas já cursadas (seja em nível de graduação, seja em pós-graduação). Contudo, percebe-se diferença substancial na porcentagem de pessoas que tiveram contato com essa metodologia em disciplinas em seus cursos: para os entrevistados com graduação a quase totalidade teve acesso ao conhecimento quantitativo por esse meio, enquanto a porcentagem cai para menos de $70 \%$ entre os respondentes com/na pós-graduação. É possível que isso se deva ao fato de que alunos da pós-graduação são oriundos de diferentes cursos de graduação, que podem não abordar a parte quantitativa em seu currículo, ou podem fazê-lo de forma bastante pontual.

Ainda, analisando os dados das Tabelas 5 e 6, destaca-se a porcentagem de autodidatas na pós-graduação que buscam conhecimento quantitativo. Tal comportamento pode ser compreendido se essa resposta for somada à de acesso mais restrito à formação em metodologia quantitativa dentro das disciplinas cursadas em seu(s) curso(s) realizado(s) até então. Dessa forma, em caso de não ser ofertado esse tipo de conhecimento durante a formação acadêmica, buscar sanar essa lacuna de forma autodidata, ou mesmo em cursos extracurriculares, é um comportamento esperado. Porém, como se sabe, cursos sobre métodos quantitativos costumam implicar um investimento bastante alto, razão pela qual buscar conhecimento de forma autodidata pode responder melhor. Outro ponto capaz de esclarecer esse perfil é que há alunos que estão na pós-graduação em Ciência Política da UFRGS e que foram graduados pela própria instituição. Assim, é possível que sua formação em 
metodologia quantitativa seja referente a disciplinas da graduação (que, conforme indicam os dados, possui papel decisivo no ensino de metodologia quantitativa desses profissionais).

As próximas tabelas mostram a relação do nível de formação dos estudantes com o conhecimento do software SPSS $^{\circledast}$, com o mapeamento de onde foi adquirido esse conhecimento e com o conhecimento de outros softwares de pesquisa.

Tabela 7 - Nível de formação X Conhece o software SPSS ${ }^{\circledR}$ (\%)

\begin{tabular}{l|c|c}
\hline Resposta & $\begin{array}{c}\text { Graduação em } \\
\text { Ciências Sociais* }\end{array}$ & $\begin{array}{c}\text { Pós- graduação em } \\
\text { Ciência Política* }^{* *}\end{array}$ \\
\hline Sim & 97 & 70 \\
Não & 3 & 30 \\
Total & 100 & 100 \\
\hline \multicolumn{3}{c}{${ }^{*} n=30^{* *} n=20$}
\end{tabular}

Fonte: Pesquisa Metodologia de Pesquisa: bases, técnicas e complementação dos protocolos quantitativo e qualitativo de conhecimento (2012).

A Tabela 7 mostra que a quase totalidade dos alunos de graduação (97\%) conhece o software SPSS ${ }^{\circledast}$, enquanto o percentual de alunos de pós-graduação que conhecem essa ferramenta cai para $70 \%$. Ao lembrar que há alunos que estão na pós-graduação e que são oriundos da graduação em Ciências Sociais da UFRGS, pode-se supor que parte do seu contato com o SPSS ${ }^{\circledR}$ pode ter-se dado ainda na graduação. Os alunos de pós-graduação que não conhecem o software são oriundos dos cursos de graduação em História, Relações Internacionais e Teologia, o que remete à necessidade de maior atenção ao quadro de aprendizagem dos alunos de pós-graduação. Além disso, o fato de $97 \%$ dos alunos de graduação terem conhecimento da ferramenta de trabalho citada mostra que, mesmo o ensino de metodologia não sendo considerado robusto (como se verificará mais adiante), os recursos humanos formados nesse nível de ensino receberam treinamento (ou, ao menos, tomaram conhecimento) para utilizar a ferramenta. Nesse sentido, caso venham a trabalhar com demandas que requeiram a utilização de uma ferramenta de análise quantitativa, esses profissionais saberão o que buscar (e como utilizar).

Dentre os respondentes que afirmaram conhecer o SPSS ${ }^{\circledast}$, indagou-se de que forma esse conhecimento foi adquirido. A próxima tabela trata dessa questão. 
Tabela 8 - Nível de formação X Esse conhecimento do SPSS ${ }^{\circ}$ advém de (\%) ${ }^{1}$

\begin{tabular}{l|c|c}
\hline \multicolumn{1}{c|}{ Conhecimento prévio } & $\begin{array}{c}\text { Graduação em Ciências } \\
\text { Sociais* }\end{array}$ & $\begin{array}{c}\text { Pós- graduação em Ciência } \\
\text { Política** }^{* *}\end{array}$ \\
\hline Disciplinas cursadas na graduação & 93 & 50 \\
Disciplinas cursadas no mestrado & 3 & 25 \\
Cursos extracurriculares & 10 & 25 \\
Autodidata & 3 & 33 \\
Participação em pesquisas & 28 & 25 \\
\hline \multicolumn{2}{l}{} \\
\end{tabular}

1 Os dados da tabela não somam $100 \%$ por se tratar de questão de múltipla escolha.

Fonte: Pesquisa Metodologia de Pesquisa: bases, técnicas e complementação dos protocolos quantitativo e qualitativo de conhecimento (2012).

A Tabela 8 reúne diferentes atividades em que os alunos poderiam ter tido contato com o SPSS ${ }^{\circledR}$, e em cada atividade verifica-se a porcentagem de quem respondeu positivamente à situação por nível educacional. Tanto entre os alunos de graduação quanto entre os de pós-graduação, o conhecimento do SPSS está mais relacionado com as aulas de graduação do que com as demais possibilidades (tal questão quanto à pós-graduação é tratada logo a seguir). A segunda situação mais citada como responsável pelo contato dos alunos de graduação com o $\mathrm{SPSS}^{\oplus}$ foi a atuação em pesquisa (como bolsista de iniciação científica, pesquisador em grupo de trabalho ou em grupos de pesquisa, ou mesmo fora da academia). Nesse sentido, pode-se dizer que a atuação dos alunos em pesquisa é de extrema importância para a sua formação, pois a torna mais completa, resultando em profissionais mais aptos a enfrentarem o mercado de trabalho.

Para 50\% dos alunos de pós-graduação, seu conhecimento está relacionado às disciplinas cursadas na graduação. Tal dado vai ao encontro da suposição, levantada anteriormente, de que o contato dos alunos de pós-graduação com o SPSS ${ }^{\circledR}$ deu-se ainda na graduação. Para $25 \%$ dos alunos de pós-graduação, o conhecimento foi obtido por meio de disciplinas desse nível de ensino. Também são os alunos de pós-graduação que mais fazem cursos extracurriculares, tomando contato pela primeira vez com o SPSS ${ }^{\oplus}$ nessas ocasiões. Ainda, talvez pela maior defasagem de aprendizagem, os respondentes com pós-graduação apresentam maior porcentagem de autodidatas do que os de entrevistados com graduação.

Levando-se em conta a considerável porcentagem de participantes de pesquisas e de autodidatas, torna-se importante verificar se outros softwares, tanto quantitativos quanto qualitativos, são conhecidos pela população estudada. Na tabela seguinte, é apresentada a distribuição dos graduandos e de pós-graduandos quanto 
ao conhecimento de outros softwares de pesquisa.

Tabela 9 - Nível de formação X Ouviu falar em outros softwares (qualitativos ou quantitativos) de pesquisa (\%)?

\begin{tabular}{l|c|c}
\hline \multicolumn{1}{c|}{ Possui conhecimento } & $\begin{array}{c}\text { Graduação em Ciências } \\
\text { Sociais }\end{array}$ & $\begin{array}{c}\text { Pós-graduação em Ciên- } \\
\text { cia Política** }\end{array}$ \\
\hline Sim & 70 & 55 \\
Não & 23 & 40 \\
Não sabe & 7 & 5 \\
Total & 100 & 100 \\
\hline \multicolumn{2}{c}{${ }^{*} n=30^{* *} n=20$}
\end{tabular}

Fonte: Pesquisa Metodologia de Pesquisa: bases, técnicas e complementação dos protocolos quantitativo e qualitativo de conhecimento (2012).

A Tabela 9 indica que os alunos vinculados à graduação (70\%) são os que mais sabem da existência de outros softwares de pesquisa. Mesmo assim, a parcela de alunos de graduação que não conhecem outro software de pesquisa não pode ser avaliada como baixa, especialmente se considerarmos que mais da metade dos respondentes em nível de graduação estava se formando no bacharelado em Ciências Sociais $^{7}$. Também chama atenção o fato de $40 \%$ dos alunos de mestrado não conhecerem outros softwares de pesquisa, seja de análise quantitativa, seja de análise qualitativa. Esse quadro indica, mais uma vez, que o ensino de metodologia, nos dois níveis de ensino, carece de atividades que o reforcem, ideia aplicável a ambas as metodologias, quantitativa e qualitativa, pois a questão permitia posicionar-se tanto em relação a uma quanto em relação à outra. Com os avanços informacionais, talvez seja considerado até inadmissível que um recurso humano com formação recente na área em destaque ignore esse tipo de ferramenta.

Para além do nível de aprendizado, considera-se relevante averiguar o interesse dos alunos no aprendizado de métodos de pesquisa quantitativa durante sua formação acadêmica. Os dados revelam que $46 \%$ do total de entrevistados (50) gostariam de realizar um curso sobre técnicas quantitativas de pesquisa com o objetivo de aperfeiçoar o conhecimento que já detêm sobre o assunto. Outros 40\% revelam o mesmo interesse, porém, com o intuito de conhecer uma nova forma de trabalho. Entretanto, $14 \%$ da população simplesmente não têm interesse em realizá-lo. Não foi indagado o motivo da falta de interesse nesse tipo de aperfeiçoamento profissional.

Esses dados, separados por nível de formação, encontram-se na Tabela 10. 
Tabela 10 - Nível de formação X Interesse em curso de técnicas quantitativas (\%)?

\begin{tabular}{l|c|c}
\multicolumn{1}{c|}{ Possui conhecimento } & $\begin{array}{c}\text { Graduação em } \\
\text { Ciências Sociais* }\end{array}$ & $\begin{array}{c}\text { Pós- graduação em } \\
\text { Ciência Política** }\end{array}$ \\
\hline $\begin{array}{l}\text { Não teria interesse } \\
\text { Conhecer nova técnica de trabalho }\end{array}$ & 7 & 25 \\
$\begin{array}{l}\text { Aperfeiçoar conhecimento que já possui sobre } \\
\text { técnicas quantitativas }\end{array}$ & 60 & 50 \\
Total & 100 & 100 \\
\hline
\end{tabular}

${ }^{*} n=30{ }^{* *} n=20$

Fonte: Pesquisa Metodologia de Pesquisa: bases, técnicas e complementação dos protocolos quantitativo e qualitativo de conhecimento (2012).

A partir dos dados expostos na tabela acima, verifica-se que os alunos da pós-graduação são os que menos demonstram interesse em um curso de técnicas de pesquisa quantitativa. Ao mesmo tempo, são eles que, majoritariamente, teriam interesse em conhecer uma nova forma de trabalho (50\%). Já para os alunos de graduação, como, em sua maioria, há o conhecimento de técnicas quantitativas, $o$ principal interesse está alocado em aperfeiçoar esse conhecimento.

Após a análise dos objetivos anteriormente citados, passa-se à análise da qualificação do ensino de metodologia segundo a visão dos alunos. Para tanto, seguem as Tabelas 11 e 12 .

Tabela 11 - Sobre metodologia, você considera que, nas diferentes disciplinas, esse assunto é (\%)?

\begin{tabular}{l|c|c|c}
\hline \multicolumn{1}{c|}{ Opinião } & Costumeiramente abordado* $^{*}$ & Bem abordado* $^{*}$ & Suficientemente abordado* $^{*}$ \\
\hline Sim & 36 & 50 & 18 \\
Não & 64 & 50 & 82 \\
Total & 100 & 100 & 100 \\
\hline \multicolumn{2}{|c}{} \\
\end{tabular}

Fonte: Pesquisa Metodologia de Pesquisa: bases, técnicas e complementação dos protocolos quantitativo e qualitativo de conhecimento (2012).

Quando perguntados se "metodologia" é um assunto costumeiramente abordado em sala de aula, nas diferentes disciplinas (inclusive nas consideradas teóricas) que já completou no curso (graduação/pós-graduação), 64\% dos alunos responderam negativamente. Metade dos entrevistados respondeu também negativamente à afirmativa de que os assuntos "metodologia" e "métodos de pesquisa" são bem abordados nas aulas. Assim, as respostas que mais preocupam são as que indicam que o assunto é suficientemente abordado: $81 \%$ da população afirmam 
não serem suficientes as vezes em que se tratou de metodologia em sala de aula. Somando-se esse posicionamento aos demais, fica claro que os próprios alunos reconhecem as lacunas de sua formação e almejam que essa temática seja mais e melhor trabalhada.

A tabela a seguir apresenta um último conjunto de dados a ser tratado para compreender a qualificação do ensino de metodologia. Para tanto, com vistas a verificar em que medida os recursos humanos que estão sendo formados em Ciências Sociais e em Ciência Política na UFRGS estão preparados para atuar no mercado de trabalho, criou-se uma situação hipotética sobre a qual deveriam posicionar-se.

Tabela 12 - Logo após se formar, você recebe um convite para trabalhar como pesquisador de um grande órgão público que precisa de profissionais para auxiliar na determinação de políticas públicas (com grandes orçamentos) para o Brasil. Nesse caso, você considera que estará:

\begin{tabular}{l|c}
\hline \multicolumn{1}{c|}{ Opinião } & $\%$ \\
\hline $\begin{array}{l}\text { Completamente apto para o trabalho, pois terá conhecimento sobre as metodologias } \\
\text { de pesquisa e saberá utilizar suas várias e diferentes técnicas. }\end{array}$ & 4 \\
Mais ou menos apto, pois não terá tido contato suficiente com o assunto. & 78 \\
Inapto, já que seu contato com o assunto foi insuficiente. & 18 \\
Total & 100 \\
\hline
\end{tabular}

Fonte: Pesquisa Metodologia de Pesquisa: bases, técnicas e complementação dos protocolos quantitativo e qualitativo de conhecimento (2012).

Os dados mostram que apenas $4 \%$ dos entrevistados sentem-se completamente aptos a trabalhar como pesquisador. A maior parcela (78\%) sente-se apta em parte. É emblemático que, de uma formação com falhas, $18 \%$ dos entrevistados considerem-se inaptos a trabalhar como pesquisador, determinando a aplicação de recursos públicos (o que deveria ser componente da formação do cientista social e do cientista político). Essas informações reforçam, portanto, que há limitações no ensino de metodologia de pesquisa ofertado até o momento aos alunos de graduação em Ciências Sociais e de pós-graduação em Ciência Política.

\section{Conclusões}

Os dados apresentados neste artigo evidenciam que a maior parte dos alunos pesquisados possui algum tipo de conhecimento sobre métodos quantitativos, mas uma parcela dessa população não se encontra preparada para o mercado de trabalho. Foi possível, nessa perspectiva, identificar problemas, principalmente em 
relação ao conhecimento do protocolo de natureza quantitativa, que faz parte da formação de cientista social e de cientista político. Corrobora essa afirmação o fato de que, quando solicitado, foram mencionadas técnicas de pesquisa, em sua maioria, qualitativas.

Sobre softwares de pesquisa, grande parte dos entrevistados conhece o SPSS ${ }^{\circledR}$ (bastante utilizado na instituição) e parte significativa conhece softwares alternativos, embora seja expressiva a porcentagem dos que ignoram a existência de outras ferramentas de trabalho. Novamente, a concentração do conhecimento está na metodologia quantitativa: softwares qualitativos são mais citados do que os quantitativos.

Quando divididos entre graduação e pós-graduação, verificou-se que o primeiro grupo concentra os alunos que mais conhecem métodos quantitativos. Esse conhecimento resulta, sobretudo, das aulas frequentadas durante a graduação. Também, é relevante, para o contato com os métodos quantitativos, a atuação desses alunos em pesquisa. O mesmo ocorre em relação ao conhecimento do software SPSS ${ }^{\circledR}$ : são os graduandos os que mais conhecem a ferramenta de trabalho. A sala de aula de graduação é o meio mais acessado para ter contato com o software, tanto no caso da graduação quanto no da pós-graduação.

Ao se verificar se outros softwares de pesquisa, tanto quantitativos quanto qualitativos, são conhecidos pelos entrevistados, mais uma vez, os graduandos detêm a liderança. A maior parte dos softwares apontados é qualitativa, reforçando a disparidade do ensino de metodologia qualitativa em relação à quantitativa junto à população estudada.

O interesse em um curso de técnicas de pesquisa quantitativa mostra-se grande, tanto na graduação quanto na pós-graduação, porém, com objetivos diferentes: na pós-graduação, deseja-se conhecer uma nova técnica de trabalho; na graduação, aperfeiçoar o conhecimento já adquirido.

Os últimos dados evidenciam que, na opinião da maioria dos entrevistados, o ensino de metodologia não é tratado costumeiramente, nem pode ser considerado suficiente, registrando-se que metade dos respondentes afirmou que, quando presente, $o$ assunto é tratado de forma adequada.

Todos esses dados podem explicar o posicionamento dos entrevistados, ao responderem a situação hipotética apresentada - se estariam aptos a trabalhar com orçamentos vultosos em órgão público que precisa de profissionais para auxiliar na determinação de políticas públicas. Verificou-se que apenas $4 \%$ consideram-se aptos ao trabalho. Quanto a isso, é esperado que recursos humanos que estão entrando no mercado de trabalho não se sintam completamente aptos a cumprir determinadas funções. No entanto, julga-se porcentagem interessante a que se sente completamente inapta. 
Com base em todos esses dados, o diagnóstico sobre o ensino de metodologia revela que é preciso tratar mais fortemente esse assunto, sobretudo junto aos alunos de pós-graduação. Metodologia e técnicas de pesquisa quantitativa parecem ser mais abordadas entre os graduandos em Ciências Sociais do que entre os pós-graduandos em Ciência Política da UFRGS. Assim, acredita-se ser relevante a oferta de oficinas de metodologia de pesquisa a esses alunos e, em longo prazo, a oferta de disciplinas obrigatórias ligadas à temática. É importante que essa disciplina trate de metodologia não só em sua base teórica, mas também de forma prática, dado que a construção do conhecimento se dá na relação entre essas duas dimensões.

\section{The teaching research methodology in the perspective of students of Social and Political Science}

\section{Abstract}

This paper presentes evidence from research Research Methodology: foundations, techniques and protocols complement the quantitative and qualitative knowledge held within the framework of a post-doctoral Reuni conducted between 2011 and 2012 at Universidade Federal do Rio Grande do Sul. The research aimed to perform diagnostics on teaching research methodology among students post-graduate in Political Science and recent graduates from Social Sciences at UFRGS from the institution. Using quantitative methodology, was applied a survey to students, between the months of January and June 2012, seeking their perception on the topic discussed. The sample was selected in three stages, with the first two stages were by quotas and the third for convenience, totaling fifty questionnaires. Research has shown the need to work more systematically teaching methodology, especially quantitative methodology, with the student body.

Keywords: Instruction. Research. Methodology. Student body. UFRGS.

\section{Notas}

1 Conferir Moraes et al. (2013). Sobre o ensino de pós-graduação, verificar Oliveira e Nicolau (2012).

2 "Liberal Learning and the Political Science Major: a report to the profession" é o resultado final de uma pesquisa concluída em 1991 pela equipe do professor John Wahlke, que examinou a estrutura da educação da área de Ciência Política em nível de graduação nos Estados Unidos da América.

3 A denominação "recém-egressos" é usada para os respondentes de graduação que, tendo cumprido todos os requisitos para sua formação, estavam aptos à colação de grau. Os dados foram coletados junto a esse grupo dias antes de sua formatura, o que possibilita considerá-los ainda como parte do corpo discente da UFRGS.

4 As atividades da bolsa Reuni-UFRGS foram desenvolvidas no período de julho de 2011 a setembro de 2012.

5 O pré-teste do instrumento de pesquisa foi aplicado em alunos de graduação em Ciências Sociais por ocasião do curso de extensão "Currículo, formação e plataformas de pesquisa: Surveys - o que fazer com isso?", promovido pelo Centro de Estudantes de Ciências Sociais da UFRGS, em outubro de 2011. A importância de fazer um pré-teste do questionário está justamente em verificar "a aplicabilidade de um conjunto de perguntas” (BABBIE, 2003, p. 305). Portanto, com o pré-teste, examinaram-se as perguntas quanto à sua 
compreensão, ao seu formato, quanto à exaustão das categorias de respostas junto a um grupo de "pessoas razoavelmente adequadas para as perguntas consideradas" (BABBIE, 2003, p. 305-306).

6 A população pode ser compreendida de duas formas: a população objeto (ou simplesmente população) e a população amostrada (ou do survey). A primeira é a especificação do universo que estamos trabalhando. A segunda é a população a que realmente temos acesso e da qual retiraremos a amostra (BABBIE, 2003; SILVA, 2011).

7 Quando indagados sobre o conhecimento do software SPSS ${ }^{\circledR}, 100 \%$ dos formandos com ênfase no bacharelado responderam afirmativamente, enquanto esse percentual foi de $92 \%$ para os com ênfase na licenciatura. Todavia, quando perguntados sobre outros softwares de pesquisa, esses percentuais caíram bastante. Dos alunos do bacharelado, $75 \%$ afirmaram conhecer outros softwares; dos alunos da licenciatura, $73 \%$. Os dados mostram que outras ferramentas devem ser trabalhadas junto à população, para que esta consiga ter arcabouço técnico suficiente para dar conta de trabalhos que venham a desenvolver.

\section{Referências}

BABBIE, Earl. Métodos de pesquisas de Survey. Belo Horizonte: Ed. UFMG, 2003.

BARRETO, Aline Canuto Muniz. Egressos do curso de Ciências Sociais da UFRGS: formação acadêmica, estratégias de inserção e permanência no mercado de trabalho. 2010. $69 \mathrm{f}$. Trabalho de Conclusão de Curso (Bacharelado em Ciências Sociais) - Departamento de Sociologia, UFRGS, Porto Alegre, 2010.

LAKATOS, Eva Maria; MARCONI, Marina de Andrade. Metodologia científica. São Paulo: Atlas, 1991.

MARCONI, Marina de Andrade; LAKATOS, Eva Maria. Técnicas de pesquisa. São Paulo: Atlas, 1986.

MORAES, Luiz F. N. et al. O estado do ensino de Ciência Política dos cursos de bacharelado em Ciência Política no Brasil. In: CONGRESO LATINOAMERICANO DE CIENCIA POLÍTICA - ALACIP, 7., 2013, Bogotá. Anais ALACIP 2013. Bogotá: Universidad de Los Andes, 2013. Disponível em: <http://alacip2013.uniandes.edu.co/files/144-artigo_alacip_fernando_2013.pdf>. Acesso em: 26 out. 2013.

OLIVEIRA, Lilian; NICOLAU, Jairo. Métodos e metodologias da Ciência Política no Brasil: uma análise dos currículos de pós-graduação. In: ENCONTRO DA ASSOCIAÇÃO BRASILEIRA DE CIÊNCIA POLÍTICA - ABCP, 8., 2012, Gramado. Anais... Gramado: ABCP, 2012. Disponível em: <http://www.starlinetecnologia.com.br/abcp2012/arquivos/8_7_2012_23_23_19.pdf>. Acesso em: 26 out. 2013.

ROTMAN, Santiago. Metodología de la investigación en ciencia política. In: AZNAR, Luis; DE LUCA, Miguel. Política: cuestiones y problemas. Buenos Aires: Ariel, 2006. p. 45-82.

SEVERINO, Antônio Joaquim. A produção do conhecimento na Universidade: articulando ensino, pesquisa e extensão. 2009. Disponível em: <http://www.uba.ar/imagenes_noticias/image/ Antonio\%20Joaquin\%20Severino.pdf>. Acesso em: 26 out. 2013.

SILVA, André Luiz Carvalhal da. Introdução à análise de dados. Rio de Janeiro: E-Papers, 2011.

WAHLKE, J. C. Liberal Learning and the Political Science Major: a report to the profession. PS: Political Science and Politics, Cambridge, v. 24, n. 1, p. 48-60, mar. 1991.

ZULAUF, Monika. Ensino superior e desenvolvimento de habilidades para a empregabilidade: explorando a visão dos estudantes. Sociologias, Porto Alegre, ano 8, n. 16, p. 126-155, jul./dez. 2006. 